\title{
THE EFFECT OF TEACHER AND PEERS NEED SUPPORT ON STUDENTS' MOTIVATION IN PHYSICAL EDUCATION AND ITS RELATIONSHIP TO LEISURE TIME PHYSICAL ACTIVITY
}

\author{
ANDRE KoKA \\ Faculty of Exercise and Sport Sciences, University of Tartu, Estonia
}

\begin{abstract}
This study examined the effect of perceived need support from both the teacher and peers on students' leisure-time physical activity behaviour through the motivational processes within physical education (PE). In line with self-determination theory, it was hypothesized that perceived satisfaction of the basic psychological needs would mediate the relationships between perceived need support and students' autonomous motivation towards PE. Autonomous motivation, in turn, was expected to affect students' leisure time physical activity behaviour. School students $(n=656)$ ages $12-16$ years completed questionnaires assessing their motivational processes towards $\mathrm{PE}$, as well as their leisuretime physical activity behaviour. Results of the structural equation modelling revealed that perceived need support from both the teacher and peers had significant and positive effects on perceptions of all three basic psychological needs in PE. Only perceived need support from the teacher, however, had significant direct and indirect effect on autonomous motivation via the perceived competence. Furthermore, only perceived need support from the teacher has indirect effect on students' leisure-time physical activity behaviour through the perceived autonomy and competence. Results suggest that perceived need support from both the teacher and peers are essential antecedents to perceived psychological needs satisfaction in PE, whereas only perceived need support from the teacher is essential antecedent to autonomous motivation towards $\mathrm{PE}$, but also students' leisure-time physical activity behaviour.
\end{abstract}

Keywords: adolescents, psychological needs, self-determination, significant others, structural equation modelling 


\section{INTRODUCTION}

The decreasing trend in participation in physical activity during the adolescence [18] has provoked a line of research investigating the possible factors and mechanisms through which the promotion of physical activity among youth would be achieved. The research, based on social-cognitive models of motivation - self-determination theory [7] and theory of planned behaviour [1] - have demonstrated that students' motivational processes in school physical education (PE) can affect motivation as well as intentions for and actual leisure-time physical activity behaviour [2, 4, 8, 11, 12, 24]. Much of this research has focused on the interpersonal behaviours of teachers in PE lessons. For example, Hagger et al. [11, 12] and Barkoukis et al. [2] proposed a motivational sequence in which students' perceptions of autonomy support, as provided by their teacher in PE, predicted motivation as well as intentions for and actual leisure-time physical activity behaviour through the motivational processes in PE.

The perceived autonomy support from the teacher, however, should not be considered as the sole source of perceived autonomy support influencing students' autonomous motivation in PE [22]. The research has demonstrated that, in addition to the teacher's support, the quality of students' relationships with their closest friends as well as the extent to which they feel accepted by their peers in PE classes, also affected positively students' motivation via the perceived satisfaction of the need for relatedness [5]. This confirms that both the teacher and peers comprise the social context of PE and they have independent roles in motivational processes [6]. Based on the latter results, one may argue that when students perceive their peers' behaviour in PE as autonomysupportive, this will likely lead to the formation of autonomous motivation.

The present study, therefore, aims to extend the previous studies by incorporating perceived need support from both the teacher and peers in PE as influences on students' leisure-time physical activity behaviour through the motivational processes within PE. Based on the hypotheses from self-determination theory [7] and results of the previous research conducted in PE [2, 11, 12, 20, $25,26,27,28]$, the following hypotheses were formulated. Specifically, as illustrated in Figure 1, it was hypothesized that perceived need support from both the teacher and peers, comprising perceived autonomy support (i.e., allowing the initiation of students' own behaviour and acknowledging their feelings, providing choice, and positive feedback), perceived competence support (i.e., making students feel like they are good at PE), and perceived relatedness support (i.e. encouraging students to work together in PE), will have significant direct and positive effect on perceived satisfaction of the needs for autonomy, competence, and relatedness. 


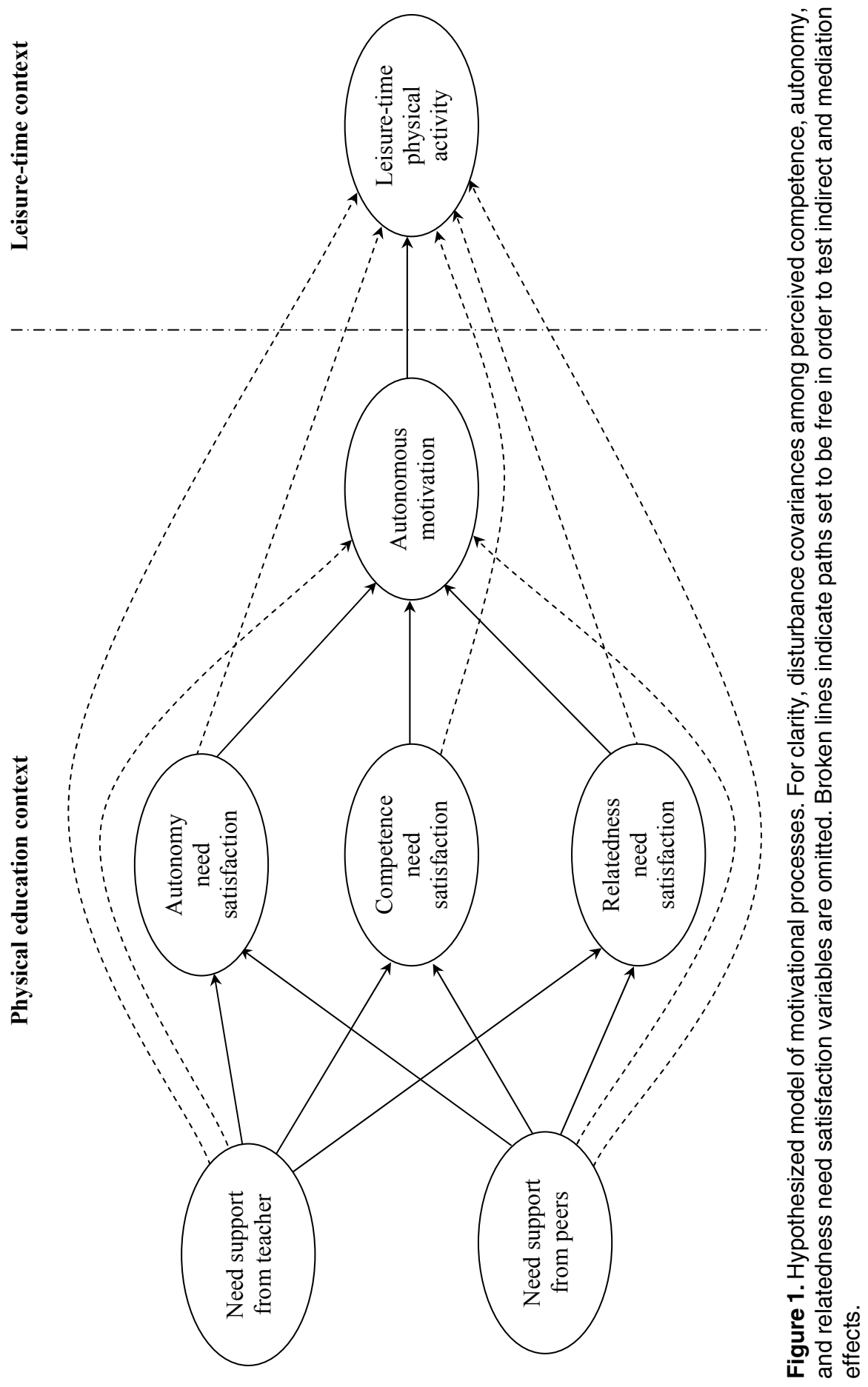


The perceived need satisfaction variables will have significant direct and positive effects on autonomous motivation towards PE. The expected significant association of perceived need support from both the teacher and peers with autonomous motivation towards PE will be mediated by the perceived need satisfaction variables. The autonomous motivation towards PE was expected to influence leisure-time physical activity behaviour. Finally, it was expected that the effects of perceived need support from both the teacher and peers on students' leisure-time physical activity would be indirect through the motivational processes in PE.

\section{MATERIALS AND METHODS}

\section{Participants and procedures}

Participants were 656 secondary school students ( 310 boys and 346 girls) ages $12-16$ years $(\mathrm{M}$ age $=13.58, \mathrm{SD}=0.62)$ from several schools located in southeast of Estonia. Permission to carry out the study was obtained from the headmasters. Parental consent was obtained for all children as well. Questionnaires were administered in quiet classroom conditions that took approximately $15 \mathrm{~min}$ to complete. Students were assured that their answers would remain confidential.

\section{Measures}

Perceived Psychological Need Support from the Teacher and Peers in PE. To assess the students' perceptions of autonomy, competence, and relatedness support from the teacher and peers in PE, 15-item need support scale developed by Standage et al. [25] was used. All items were preceded by the stem, "In this PE class ..., and students responded on 7-point scale anchored by 1 (strongly disagree) to 7 (strongly agree). Example items are: “... I feel that my [salient referent(s)] listen(s) to how I would like to do things" (autonomy support; six items), “... my [salient referent(s)] make(s) me feel like I am able to do the activities in class" (competence support; four items), and "... I feel that my [salient referent(s)] is/are friendly towards me” (relatedness support; five items) with 'PE teacher' or 'peers' as the salient referent in each of the two scale, respectively. The proposed three-factor structure of both scales have been previously supported via confirmatory factor analysis [29]. In this study, the Cronbach's alphas for autonomy support, competence support, and relatedness support from the teacher and peers subscales were $0.86,0.79$, and 0.87 and $0.87,0.87$, and 0.88 , respectively. Averaged scales for autonomy, competence, 
and relatedness need support from the teacher and peers, respectively, were used as indicators of a single latent factor for need support from the teacher and peers, respectively, in subsequent analyses.

Perceived Autonomy Need Satisfaction. Students' perceived satisfaction of the need for autonomy in PE was assessed using a 3-item scale [16]. An example item included "I feel that I have a say in what I do when participating in PE". Students responded on a 7 -point scale anchored by 1 (strongly disagree) to 7 (strongly agree). Cronbach's alpha coefficient for perceived autonomy need satisfaction items in this study was 0.80 .

Perceived Competence Need Satisfaction. Students' perceived satisfaction of the need for competence in PE was assessed using a 5-item subscale form the Intrinsic Motivation Inventory [17]. An example item included "I think I am pretty good at PE" and students responded on 7-point scale anchored by 1 (strongly disagree) to 7 (strongly agree). In the present study, Cronbach's alpha coefficient for perceived competence need satisfaction items was 0.89 .

Perceived Relatedness Need Satisfaction. Students' perceived satisfaction of the need for relatedness was measured using five items [16]. Students responded to the items preceded by the stem: "In PE classes I feel ...", followed by five descriptors: (e.g., “... understood”, “... safe”, “... supported”). Students responded on 7-point scale anchored by 1 (strongly disagree) to 7 (strongly agree). Cronbach's alpha coefficient for perceived relatedness need satisfaction items in this study was 0.93 .

Motivational Regulations. The Perceived Locus of Causality scale, developed by Goudas, Biddle, and Fox [10], was used to assess students' different types of motivational regulations towards PE. Students responded to the items preceded by the stem: "I take part in a PE classes ..., followed by different reasons. All subscales included four items. Example items are: “... because I enjoy doing PE” (intrinsic motivation), “... because I value the benefits of PE” (identified regulation), “... because I will feel guilty if I do not” (introjected regulation), “... because the teacher says I should" (external regulation), and “..., however, I really do not know why" (amotivation). Students responded on 7-point scale ranging from 1 (strongly disagree) to 7 (strongly agree). In the present study, the Cronbach's alphas for intrinsic motivation, identified regulation, introjected regulation, external regulation, and amotivation subscales were 0.90 , $0.84,0.77,0.68$, and 0.87 , respectively. In order to examine relations among the constructs in the hypothesized model, consistent with previous studies in $\mathrm{PE}$ [16], four types of motivation and amotivation were integrated into a single index by calculating a self-determination index (SDI) that reflects autonomous motivation. Accordingly, each item from subscales was weighted as follows: 
intrinsic motivation $(+3)$, identified regulation $(+2)$, introjected regulation $(-1)$, extrinsic regulation $(-2)$, and amotivation $(-3)$, and four SDI items were calculated based on the weighted composite of these scores. These items were used as indicators of a single latent autonomous motivation factor in subsequent analyses.

Leisure-time Physical Activity. Students' leisure-time physical activity behaviour was assessed using an adapted version of Leisure-Time Exercise Questionnaire [9]. Participants rated their behavioural frequency on two items (e.g., "In the course of the past 2 weeks, how often have you participated in vigorous physical activities for $30 \mathrm{~min}$ at a time?", using 6-point scale with endpoints of never (1) and everyday (6). In this study, the Cronbach's alpha for the twoitem scale was 0.75 .

\section{Data Analyses}

A structural equation modelling (SEM) analyses with latent constructs were conducted to test the adequacy of the proposed model outlined in Figure 1, using LISREL 8.51 software [14]. According to the recommendations by $\mathrm{Hu}$ and Bentler [13], the following goodness of fit indices were used to assess the adequacy of the proposed model: the chi-square test $\left(\chi^{2}\right)$, Incremental Fit Index (IFI), Comparative Fit Index (CFI), Non-Normed Fit Index (NNFI), and Root Mean Square Error of Approximation (RMSEA). The values $\geq 0.95$ for IFI, CFI, and NNFI, and values $\leq 0.06$ for RMSEA are taken to reflect an acceptable fit [13]. In all analyses, in testing for significant indirect and mediation effects, the criteria proposed by Baron and Kenny [3] were followed.

\section{RESULTS}

The correlations among the latent study variables are presented in Table 1, which represent the input in the SEM analyses. The significant multivariate skewness $(29.39, \mathrm{p}<0.01)$ and kurtosis $(480.05, \mathrm{p}<0.01)$ indicated that variables were highly abnormal. Therefore, according to Satorra and Bentler [23], a robust maximum likelihood estimation method was employed that enables to prevent Type I error, because this method adjusts the chi-square statistics and the standard errors under conditions of non-normality. 
Table 1. Factor correlations among the study variables $(n=656)$

\begin{tabular}{llllllll}
\hline & $\mathbf{1}$ & $\mathbf{2}$ & $\mathbf{3}$ & $\mathbf{4}$ & $\mathbf{5}$ & $\mathbf{6}$ & $\mathbf{7}$ \\
\hline $\begin{array}{l}\text { 1. Perceived need support from } \\
\text { teacher }\end{array}$ & - & & & & & & \\
\hline $\begin{array}{l}\text { 2. Perceived need support from } \\
\text { peers }\end{array}$ & 0.44 & - & & & & & \\
\hline 3. Autonomy need satisfaction & 0.74 & 0.43 & - & & & & \\
\hline 4. Competence need satisfaction & 0.48 & 0.30 & 0.53 & - & & & \\
\hline 5. Relatedness need satisfaction & 0.42 & 0.74 & 0.45 & 0.42 & - & & \\
\hline 6. Autonomous motivation & 0.57 & 0.21 & 0.51 & 0.52 & 0.26 & - & \\
\hline 7. Leisure-time physical activity & 0.20 & 0.13 & 0.27 & 0.33 & 0.13 & 0.21 & - \\
\hline
\end{tabular}

Note: All correlations are statistically significant $(p<0.01)$

The hypothesized model exhibited acceptable fit with the data $\left[\chi^{2}\right.$ $(131)=451.27, \mathrm{p}<0.01, \mathrm{CFI}=0.96, \mathrm{IFI}=0.96, \mathrm{NNFI}=0.95, \mathrm{RMSEA}=0.061$, confidence interval $\left(\mathrm{CI}_{90}\right)$ for RMSEA range $\left.=0.055-0.067\right]$. The standardized path coefficients for the free parameters are shown in Figure 2, and standardized parameter estimates of indirect effects are presented in Table 2 . The model accounted for $56 \%, 24 \%$, and $56 \%$ of the variance in perceived satisfaction of the needs for autonomy, competence, and relatedness, respectively, and $41 \%$ and $13 \%$ of the variance in autonomous motivation towards PE and leisuretime physical activity behaviour, respectively.

Table 2. Standardized parameter estimates of endirect iffects $(n=656)$

\begin{tabular}{ll}
\hline Parameter & b \\
\hline Perceived need support from teacher $\rightarrow$ Autonomous motivation & $0.19^{*}$ \\
\hline Perceived need support from teacher $\rightarrow$ Leisure-time physical activity & $0.24^{*}$ \\
\hline Perceived need support from peers $\rightarrow$ Autonomous motivation & 0.04 \\
\hline Perceived need support from peers $\rightarrow$ Leisure-time physical activity & 0.00 \\
\hline Autonomy need satisfaction $\rightarrow$ Leisure-time physical activity & 0.00 \\
\hline Competence need satisfaction $\rightarrow$ Leisure-time physical activity & 0.01 \\
\hline Relatedness need satisfaction $\rightarrow$ Leisure-time physical activity & 0.00 \\
\hline
\end{tabular}

Note: * $p<0.01$ 
The effect of teacher and peers need support on students' motivation I 55

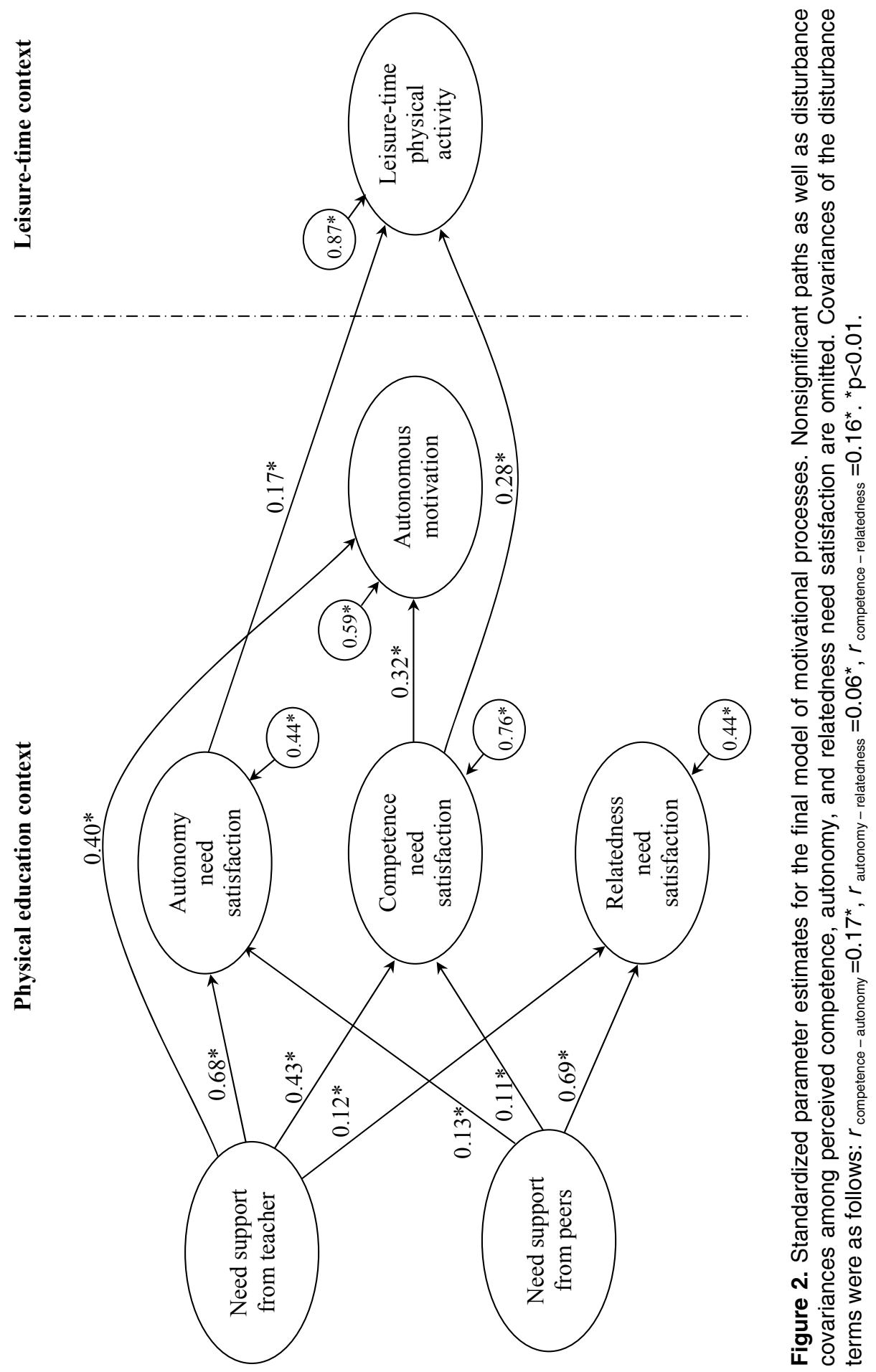




\section{Relationships in the model}

As hypothesized, perceived need support from the PE teacher and peers had direct and positive effects on the perceived need satisfaction variables of autonomy $(\beta=0.68, p<0.01$ and $\beta=0.13, p<0.01$, for perceived need support from the teacher and peers, respectively), competence $(\beta=0.43, p<0.01$ and $\beta=0.11$, $\mathrm{p}<0.01$, for perceived need support from the teacher and peers, respectively), and relatedness $(\beta=0.12, p<0.01$ and $\beta=0.69, p<0.01$, for perceived need support from the teacher and peers, respectively).

Only the significant direct effect of perceived satisfaction of the need for competence $(\beta=0.30, p<0.01)$ on autonomous motivation towards $P E$, inversely to the nonsignificant effects of perceived satisfaction of the need for autonomy $(\beta=0.08, p>.05)$ and relatedness $(\beta=0.01, p>.05)$, was accordance with the hypothesis. The indirect effect of perceived need support from the teacher $(\beta=0.19, p<0.01)$, but not from peers $(\beta=0.04, p>0.05)$, on autonomous motivation was significant, supported the hypothesis only partially. However, a significant direct effect of perceived need support from the teacher on autonomous motivation also emerged $(\beta=0.40, p<0.01)$, indicated that any mediation of the effect of perceived need support from the teacher on autonomous motivation would be partial. To test the mediation of the effect of perceived need support from the teacher on autonomous motivation by perceived satisfaction of the need for competence, the path from perceived competence need satisfaction to autonomous motivation was fixed to zero. Results indicated that the relationship between perceived need support from the teacher and autonomous motivation increased from $\beta=0.40(p<0.01)$ to $\beta=0.43(p<0.01)$, indicated the existence of partial mediation. Although the model in which the path from perceived competence need satisfaction to autonomous motivation was fixed to zero provided an acceptable fit to the data $[\chi 2(132)=515.30$, $\mathrm{p}<0.001, \mathrm{CFI}=0.96, \mathrm{IFI}=0.96, \mathrm{NNFI}=0.95, \mathrm{RMSEA}=0.067, \mathrm{CI}_{90}$ for $\mathrm{RMSEA}$ range $=0.061-0.073]$, it did provide significantly worse fit to the data compared with the hypothesized model $\left[\chi_{\text {diff }}^{2}(1)=64.03, p<0.01\right]$. As a result, the total effect of perceived need support from the teacher on autonomous motivation (total effect, $\beta=0.59$, $\mathrm{p}<0.01$ ) was both direct and indirect via perceived satisfaction of the need for competence, supported thus the mediational hypothesis only partially.

Results indicated, not consistent with the hypothesis, that autonomous motivation towards PE did not predict leisure-time physical activity behaviour $(\beta=0.02, p>0.05)$. There were, however, significant direct effects of perceived satisfaction of the needs for autonomy $(\beta=0.17, \mathrm{p}<0.01)$ and competence $(\beta=0.28, p<0.01)$ on leisure-time physical activity behaviour. Since the 
significant direct effects of perceived satisfaction of the needs for autonomy and competence on leisure-time physical activity emerged, separate tests were conducted in order to specify the route most responsible for the significant indirect effect of perceived need support from the teacher $(\beta=0.24, p<0.01)$ on leisure-time physical activity behaviour. Specifically, first the effect of perceived satisfaction of the need for autonomy on leisure-time physical activity behaviour was fixed to zero, to examine the indirect effect of perceived need support from the teacher on leisure-time physical activity behaviour via the perceived satisfaction of the need for competence. Then the effect of perceived satisfaction of the need for competence on leisure-time physical activity behaviour was fixed to zero, to examine the indirect effect of perceived need support from the teacher on leisure-time physical activity behaviour via the perceived satisfaction of the need for autonomy. Separate tests revealed the larger indirect effect $(\beta=0.27, p<0.01)$ via the perceived satisfaction of the need for autonomy, relative to the indirect effect $(\beta=0.14, p<0.01)$ via the perceived satisfaction of the need for competence.

\section{DISCUSSION}

The present study tested the model aimed to explain the effects of perceived need support from the teacher and peers on students' leisure-time physical activity behaviour through the motivational processes within PE.

Results revealed, accordance with the hypothesis, that perceived need support from both the teacher and peers positively predicted perceived satisfaction of the needs for autonomy, competence, and relatedness in PE. In terms of the effect of perceived need support from the teacher, this is consistent with past research conducted in PE $[2,20,25,26,27,28]$. Results revealed, however, that the magnitude of the effects of perceived need support from the teacher and peers on need satisfaction variables were different. Specifically, perceived need support from the teacher had stronger effect on perceived satisfaction of the needs for competence and autonomy, whereas perceived need support from peers had stronger effect on perceived satisfaction of the need for relatedness. This is, actually, not surprising, because research has shown that children in this age rely more heavily on teacher's feedback, compared with peers, as a source of their perceived competence [30]. The stronger effect of perceived need support from the teacher, compared with peers, on perceived satisfaction of the need for autonomy can be attributed to the teacher's person who is the main authority in classes and thereby able to facilitate students' feelings of autonomy by, for example, including them into the decision-making processes. The possible 
explanation for the weaker effect of perceived need support from the teacher on perceived satisfaction of the need for relatedness, compared with peers, could be that it is rather rare to have really close relationships between teachers and students at this age [15].

Results indicated, not entirely consistent with the hypothesis that only perceived satisfaction of the need for competence did contribute significantly to the formation of autonomous motivation towards PE, while perceived satisfaction of the needs for autonomy and relatedness did not. As regards to the nonsignificant effect of perceived satisfaction of the need for relatedness on autonomous motivation, this finding is not so surprising as several past studies conducted in school PE have also shown the same phenomena [2, 27, 28]. As argued by Deci and Ryan [7], the reason for this could be probably the more distal role of the need for relatedness in enhancing the autonomous motivation towards PE, compared with the needs for competence and autonomy. The nonsignificant contribution of perceived satisfaction of the need for autonomy to the formation of autonomous motivation towards $\mathrm{PE}$ is not in line with many previous studies conducted in school $\mathrm{PE}$, found that satisfaction of the need for autonomy significantly predicted autonomous motivation $[2,26,27$, 28]. However, Ntoumanis [19] and Koka and Hagger [16] also found nonsignificant contribution of perceived satisfaction of the need for autonomy to the formation of autonomous motivation towards PE. The latter authors argued that $\mathrm{PE}$ teachers are usually required to follow very prescriptive curriculum that does not allow them to provide much choice and opportunities for students' initiatives. Furthermore, it is also possible that PE teachers do not feel really skilled in the use of autonomy-supportive instructional behaviours that would facilitate the students' feelings of autonomy in classes. This may be probably the case with PE teachers involved in the present study.

The results revealed, not entirely consistent with the hypothesis that perceived need support from the teacher, but not from peers, had significant indirect effect on students' autonomous motivation towards PE through the satisfaction of the need for competence. In terms of the effect of perceived need support from the teacher, this is in line with previous studies in PE showed that providing basic need support increases need satisfaction of students which, in turn, facilitate formation of autonomous motivation towards activity $[2,20,25$, $26,27,28]$. The nonsignificant indirect effect of perceived need support from peers on autonomous motivation towards $\mathrm{PE}$ confirms the finding of Cox et al. [5], demonstrated that in terms of motivational experiences in PE, students' interaction with their teachers are more important than interaction with their peers. The additional significant direct effect of perceived need support from 
the teacher on autonomous motivation towards PE suggests that perceived need support from the teacher influences autonomous motivation towards PE via two processes: direct, impulsive route and an indirect, reflective route via the mediation of satisfaction of the need for competence. This finding is in line with recent research in a PE context [16], found that different perceived teaching behaviours affected autonomous motivation directly and indirectly via satisfaction of one or more of the basic needs.

Results revealed, inconsistent with the hypothesis, that autonomous motivation towards PE did not predict students' leisure-time physical activity behaviour. Instead, perceived satisfaction of the needs for autonomy and competence in PE had significant direct and positive effects on leisure-time physical activity behaviour. This is in line with the results of the study by Barkoukis et al. [2]. Although results of their path analysis did not specify nor find significant direct paths from perceived satisfaction of the needs for autonomy and competence in a PE context to students' leisure-time physical activity behaviour, they did find significant correlation between leisure-time physical activity behaviour and perceived satisfaction of the needs for autonomy and competence, but not for perceived relatedness. Results of the present study further specified that perceived satisfaction of the need for autonomy was most responsible for the mediation of the relationship between perceived need support from the PE teacher and students' leisure-time physical activity behaviour. This suggests that perceived need support from the teacher that is generally associated with encouraging the initiation of students' own behaviour and providing choice and rationale, is essential antecedent to students' perceived satisfaction of the need for autonomy in PE, but more importantly, to their leisure-time physical activity behaviour.

This study is not without limitations. One of the major limitations is the omission of measures about students' autonomous motivation towards leisuretime physical activity, as well as situation-specific beliefs and judgements about leisure-time physical activity behaviour, specified in the theory of planned behaviour [1]. Past studies have demonstrated that autonomous motivation towards PE has an impact to actual leisure-time physical activity behaviour indirectly through the autonomous motivation towards leisure-time physical activity and constructs from the theory of planned behaviour about leisuretime physical activity behaviour $[2,11,12,21]$. Second limitation pertains to the correlational nature of the data that precludes the inference of causality. Third, since the study was conducted on a sample of students only from one Estonian town, the findings may not be generalizable to all secondary school students. 
In conclusion, results of the present study provided support to and extended the previous PE studies in that perceived need support from both the teacher and peers are essential antecedents to perceived satisfaction of the needs for autonomy, competence, and relatedness in PE. In terms of motivational experiences in PE, as well as physical activity experiences in leisure-time, however, students' interaction with their teachers is more important than interaction with their peers. Results revealed that perceived need support from the PE teacher is primarily involved in an autonomy-mediated route to students' leisure-time physical activity behaviour. From an applied perspective, PE teachers aiming to foster students' leisure-time physical activity behaviour should adopt a psychological need-supportive teaching style.

\section{REFERENCES}

1. Ajzen I. (1985) From intentions to actions: A theory of planned behavior. In: Kuhl J, Beckmann J (eds). Action-control: From cognition to behavior. Heidelberg: Springer, 11-39

2. Barkoukis V, Hagger MS, Lambropoulos G, Torbatzoudis H. (2010) Extending the trans- contextual model in physical education and leisure-time contexts: Examining the role of basic psychological need satisfaction. Brit J Educ Psychol, 80: 647-670

3. Baron RM, Kenny DA. (1986) The moderator-mediator variable distinction in social psychological research: Conceptual, strategic and statistical considerations. J Pers Soc Psychol, 51: 1173-1182

4. Corbin CB. (2002) Physical activity for everyone: What every physical educator should know about promoting lifelong physical activity. J Teach Phys Educ, 21: $128-144$

5. Cox A, Duncheon N, McDavid L. (2009) Peers and teachers as sources of relatedness perceptions, motivation, and affective responses in physical education. Res QExerc Sport, 80: 765-773

6. Cox A, Ullrich-French S. (2010) The motivational relevance of peer and teacher relationship profiles in physical education. Psychol Sport Exerc, 11: 337-344

7. Deci EL, Ryan RM. (2000) The "what" and "why" of goal pursuits: human needs and the self-determination of behavior. Psychol Inquiry, 11: 227-268

8. Ferrer-Caja E, Weiss MR. (2002) Cross-validation of a model of intrinsic motivation in physical education with students enrolled in elective courses. J Exp Educ, 71: 41-65

9. Godin G, Shephard RJ. (1985) A simple method to assess exercise behavior in the community. Can J Appl Sport Science, 10: 141-146

10. Goudas M, Biddle SJH, Fox KR. (1994) Perceived locus of causality, goal orientations, and perceived competence in school physical education classes. Brit J Educ Psychol, 64: 453-463 
11. Hagger MS, Chatzisarantis NLD, Barkoukis V, Wang CKJ, Baranowski J. (2005) Perceived autonomy support in physical education and leisure-time physical activity: A cross-cultural evaluation of the trans-contextual model. J Educ Psychol, 97: 376-390

12. Hagger MS, Chatzisarantis NLD, Culverhouse T, Biddle S. (2003) The processes by which perceived autonomy support in physical education promotes leisuretime physical activity intentions and behavior: A trans-contextual model. J Educ Psychol, 95: 784-795

13. Hu L, Bentler PM. (1999) Cutoff criteria for fit indexes in covariance structure analysis: Conventional criteria versus new alternatives. Struct Equ Modeling, 6: $1-55$

14. Jöreskog KG, Sörbom D. (1996) LISREL 8: User's reference guide. Chicago, IL: Scientific Software International

15. Koka A. (2013) The relationships between teaching behaviours and motivation in physical education: A 1-year longitudinal study. Scand J Educ Res, 57: 33-53

16. Koka A, Hagger MS. (2010) Perceived teaching behaviors and self-determined motivation in physical education: A test of self-determined theory. Res QExerc Sport, 81: 74-86

17. McAuley E, Duncan T, Tammen VV. (1989) Psychometric properties of the Intrinsic Motivation Inventory in a competitive sport setting: A confirmatory factor analysis. Res QExerc Sport, 60: 48-58

18. Nelson MC, Neumark-Stzainer D, Hannan PJ, Sirard JR, Story M. (2006) Longitudinal and secular trends in physical activity and sedentary behavior during adolescence. Pediatrics, 11: 1627-1634

19. Ntoumanis N. (2001) A self-determination approach to the understanding of motivation in physical education. Brit J Educ Psychol, 71: 225-242

20. Ntoumanis N. (2005) A prospective study of participation in optional school physical education using a selfdetermination theory framework. J Educ Psychol, 97: 444-453

21. Pihu M, Hein V, Koka A, Hagger MS. (2008) How students' perceptions of teacher's autonomy-supportive behaviours affect physical activity behaviour: An application of trans-contextual model. Eur J Sport Sci, 8: 193-204

22. Sage NA, Kindermann TA. (1999) Peer networks, behavior contingencies and children's engagement in the classroom. Merrill-Palmer Quart, 454: 143-171

23. Satorra A, Bentler PM. (1988) Scaling corrections for statistics in covariance structure analysis. Los Angeles: University of California at Los Angeles, Department of Psychology

24. Standage M, Duda JL, Ntoumanis N. (2003) A model of contextual motivation in physical education: Using constructs and tenets from self-determination and goal perspective theories to predict leisure-time exercise intentions. J Educ Psychol, 95: 97-110

25. Standage M, Duda JL, Ntoumanis N. (2005) A test of self-determination theory in school physical education. Brit J Educ Psychol, 75: 411-433 
26. Standage M, Duda JL, Ntoumanis N. (2006) Students' motivational processes and their relationship to teacher ratings in school physical education: A self-theory approach. Res QExerc Sport, 77: 100-110

27. Standage M, Gillison F. (2007) Students' motivational responses toward school physical education and their relationship to general self-esteem and health-related quality of life. Psychol Sport Exerc, 8: 704-721

28. Standage M, Gillison FB, Ntoumanis N, Treasure DC. (2012) Predicting students' physical activity and health-related well-being: A prospective cross-domain investigation of motivation across school physical education and exercise settings. J Sport Exerc Psy, 34: 37-60

29. Viira R, Koka A. (2012) Participation in afterschool sport: Relationship to perceived need support, need satisfaction, and motivation in physical education. Kinesiology, 44: 199-208

30. Weiss MR, Ebbeck VV, Horn TS. (1997) Children's self-perceptions and sources of physical competence information: A cluster analysis. J Sport Exerc Psy, 19: 52-7

\section{Correspondence to:}

Andre Koka

Institute of Sport and Coaching Sciences

Faculty of Exercise and Sport Sciences

University of Tartu

5 Jakobi Street, 51014 Tartu , Estonia

E-mail: andre.koka@ut.ee

Tel: +372 7375382 . 